Bol. Acad. peru. leng. 64. 2018 (175-196)

\title{
RUBÉN DARÍO Y LAS ESCRITORAS: EL CASO DE AURORA CÁCERES
}

\author{
Carmen Ruiz Barrionuevo \\ Universidad de Salamanca
}

Fecha de recepción: $\quad$ 02/08/2018

Fecha de aceptación: $\quad 31 / 10 / 2018$

Aunque la bibliografía de Rubén Darío crece de día en día, me parece sorprendente que un aspecto tan importante como sus relaciones con las escritoras no haya sido revisado. Bien es verdad que existen múltiples trabajos en los que se habla de su relación con las mujeres de carne y hueso o también de la presencia de las imágenes femeninas en su poesía, pero no se ha indagado en esa figura concreta: la de la mujer que escribe, cómo es presentada en sus crónicas o en su crítica literaria. Porque es evidente que, al igual que el hombre en el fin de siglo alcanzaba la cumbre de su superioridad al hacerse portador de los dones excelsos del arte o de la escritura - recordemos a tantos herederos del Des Esseintes de Huysmans 1 - en el caso de las mujeres, da la impresión de que no sucede lo mismo y que su imagen queda visiblemente postergada a

$1 \quad$ Nos referimos al personaje de $A$ Rebours (1884) de Joris-Karl Huysmans (1848-1907) cuya figura se reproduce con variantes en tantos relatos finiseculares. 
una actitud pasiva. Es cierto que Darío cita con veneración de modelo a «Teresa la Santa» en sus «Palabras liminares» ${ }^{2}$ a Prosas profanas pero, como sucedió en otros autores de su época, su visión de la mujer estuvo vinculada a la relación física y amorosa, y la meramente instrumental en la literatura. Hay que aclarar en su descargo que conceder que la mujer pudiera alcanzar el alto peldaño que supone la entronización del artista en paridad con el varón era algo que con dificultad asimilaban las mentes hispanas, e incluso europeas, de su época.

Resulta revelador revisar cronológicamente algunos de los trabajos de Darío en los que aparecen referencias a la actividad de las mujeres que escriben. Dos textos incluidos en La Nación de Buenos Aires nos muestran que su concepto de las escritoras oscilaba también entre la angelización y lo demoníaco, tal y como sucede en la ambigua relación que el poeta establece en sus versos con la imagen femenina. Se trata de dos artículos que llevan nombre de mujer: «Rachilde» $\mathrm{y}$ «Juana Borrero» ${ }^{3}$. De febrero de 1895 data "Rachilde», artículo que incluiría en Los raros (1896), y que sería la única pluma femenina que obtuvo tal honor, con lo que nos indica la enorme fascinación que el poeta nicaragüense sintió por su figura. Margaritte Eymery (1860-1953), más conocida por el pseudónimo de Rachilde, destacó dentro del decadentismo francés por una serie de títulos de provocadora sexualidad que causaron gran impacto en su época. La imagen de la mujer diabólica surge en el texto de Darío como esfinge maléfica, tras calificar a la francesa de «satánica flor de decadencia, picantemente perfumada, misteriosa y hechicera y mala como un pecado» ${ }^{4}$, y en ese gusto exacerbado por los contrastes de pureza y maldad, hace ver la juventud de la autora, «Y era una mujer el autor de aquel libro, una dulce y adorable virgen de diecinueve años» y una bella, "colegiala virginal», para exhibirla como una sembradora de «mandrágoras» y «venenosas orquídeas» y como «la primera

2 Dice la frase completa: «Yo le pregunto por el noble Gracián, por Teresa la Santa, por el bravo Góngora y el más fuerte de todos, don Francisco de Quevedo y Villegas». En Rubén Darío, Poesía, Caracas, Biblioteca Ayacucho 1977, p. 180.

3 Véase Susana Zanetti, Rubén Darío en La Nación de Buenos Aires 1892-1916, Buenos Aires, Eudeba, 2004, pp. 144 y 146.

4 Citamos por Rubén Darío, Obras completas, tomo II, Madrid, Afrodisio Aguado, 1950, p. 365. 
inmoralista de todas las épocas» ${ }^{5}$, una especie de Anticristo en femenino, de diabólica perversión. Darío no era original, desde luego, porque ese «malditismo» había sido explotado por Maurice Barrès (1862-1923) en su famoso y calculado prólogo a Monsieur Venus, la novela de Rachilde cuya segunda edición aparece en París en $1889^{6}$ y a la que se refiere el poeta. Como se puede observar, Darío valora sobre todo, más que su escritura, la imagen externa de Rachilde, su iconoclastia, y para ello acude al prólogo de Barrès, aunque sin aludir directamente a él, y hacerse eco con sus apreciaciones del escándalo que esa segunda edición ${ }^{7}$ había causado en los lectores franceses, llegando a concluir que es «un libro de demoniomanía», «impregnado de una desconocida u olvidada lujuria», y una «esencia de perversidad» heredada de Sade. Y todo ello forma un conjunto intencionado, ya que Monsieur Venus es «el más conocido de una serie en que desfilan las creaciones más raras y equívocas de un cerebro malignamente femenino y peregrinamente infame» ${ }^{8}$. Más que criticar la novela francesa, el texto muestra la seducción de lo prohibido, y cómo Darío, sin ver a la escritora en sus cualidades, se deja llevar por sus trasgresiones.

Muy distinto es el artículo titulado "Juana Borrero. Una María Bashkirtseff cubana», pues con este título completo se publica en $\mathrm{La}$ Nación en mayo de 1896 en el momento de la muerte de la escritora que había nacido en 1877 , y que nos ofrece la otra cara de la moneda, la imagen angelical de «una rara niña, una dulce y rara niña» desarrollando, ante el desconocimiento de su persona y obra, los testimonios varios de los poetas cubanos, como Julián del Casal (1863-1893) y Carlos

$5 \quad$ Ibid. pp. 366 y 367.

6 El prólogo de Maurice Barrès muestra expresiones que pudieron inspirar las palabras de Darío, entre otras: «Ce qui est tout à fait délicat dans la perversité de ce livre, c'est qu'il a été écrit par une jeune fille de vingt ans»; «Rachilde naquit avec un cerveau en quelque sorte infâme, infâme et coquet»; "Ce vice savant éclatant dans le rêve d'une vierge, c'est un des problèmes les plus mystérieux que je sache» (Rachilde, Monsieur Venus, Paris, Flammarion, 1977, p.5-6.

7 La primera edición había aparecido en Bruselas en 1884.

8 Rubén Darío, «Rachilde» en Obras completas, tomo II, op. cit., pp. 365 y 366.

9 Rubén Darío, «Juana Borrero» en Obras completas, tomo IV, op. cit., p. 841. Juana Borrero (1877-1896) era hija del escritor cubano Esteban Borrero Echeverría, y fue educada en un ambiente artístico. Su obra abarca pintura, poesía y un extenso epistolario. 
Pío Uhrbach (1872-1897), que transmiten la imagen de su naturaleza enfermiza y melancólica, para concluir por su cuenta:

Esas almas femeninas tienen en sí una manera de naturaleza angélica que en ocasiones se demuestra con manifestaciones visibles; son iguales en lo íntimo a los hombres elegidos del ensueño, y se elevan tanto más maravillosamente cuanto sus compañeras terrenales, inconscientes, uterinas o instrumentos de las potencias ocultas del mal, [que] son los principales enemigos de todo soñador ${ }^{10}$.

Darío ve a la autora próxima a la sensibilidad de la rusa María Bashkirtseff (1858-1884) que desarrolló su obra artística en Francia y que es famosa sobre todo por su diario, expresando la necesidad de conocer de forma más precisa su epistolario donde habría volcado del mismo modo su mundo interior. Es evidente que en todo el artículo se expresa el dolor por su temprana muerte unido a un conocimiento muy precario de su obra, que Rubén reconoce, pero también un tremendo paternalismo concesivo de la "pobre y adorable soñadora», de «la virgen que asciende a un balcón del Paraíso», imágenes de visible cursilería que remata: «mas es más hondo mi lamento si considero que ese ser especial ha desaparecido sin conocer el divino y terrible secreto del amor» ${ }^{11}$. Esa imagen de la mujer, eterna menor de edad, que necesita la protección del varón, es la que subyace en la evocación de Juana Borrero e incluso en la de Rachilde, pues como vimos también Darío se dejó llevar por el deliberado intento de Barrès al definir a su amiga, para mayor escándalo, como una «joven virgen».

A fines de siglo, en 1899, el poeta tiene la oportunidad de conocer en Madrid a una importante escritora española, muy distinta de las anteriores, Emilia Pardo Bazán (1851-1921), por la que manifestará su admiración, claro que era indiscutible que, en este caso, se trataba de una escritora con una muy larga trayectoria y además perteneciente a la aristocracia, y una de personalidades más influyentes en su época, que lo recibía y halagaba en sus salones. Al referirse a ella en su libro

10 Ibid., p. 846.

11 Ibid., p. 848. 
España contemporánea (1901), asegura que los parisinos «han oído en su idioma a una mujer muy inteligente, muy culta» que colabora con revistas parisienses, y manifiesta su desagrado contra los españoles que no querían verse representados por una mujer porque «Después de todo - me decía un espiritual colega - es lo que tenemos más presentable fuera de casa» ${ }^{12}$. Pero no olvidemos que estas crónicas que Darío envía a $L a$ Nación de Buenos Aires vienen a evidenciar la visible decadencia española después de la derrota del 98, y que el corresponsal explicita muchas veces la ausencia de escritores en la España finisecular y vencida. Y por si fuera poco añade, después de muchos elogios al físico de la escritora, entrada en edad pero atractiva, y a su don de gentes, la Condesa de Pardo Bazán se ha colocado «masculinamente entre los mejores cerebros de hombre que haya habido en España en todos los tiempos» ${ }^{13}$. No cabían, por tanto, sus grandes dotes de escritora en un cerebro de mujer y sus cualidades habían de ser masculinas, como, por otra parte, se explicaba en algunos de los grandes misóginos que proliferaron en el siglo precedente.

Sin embargo, estas opiniones más o menos concesivas y paternalistas de Darío, aunque sin beligerancia, parecen torcerse entrado el siglo XX, cuando aparecen algunas referencias a las mujeres escritoras en dos artículos: «A propósito de Mme. de Noailles» $\mathrm{y}$ «Niñas prodigios», publicado este último en julio de 1903 en La Nación de Buenos Aires. El primero lo escribe en 1902 al leer el libro de la condesa Mathieu de Noailles (1876-1933), L'ombre des jours, que acaba de aparecer en París. Aunque bien es cierto que la autora francesa no excedía de la poesía convencional y esperable en una dama de su alcurnia, la cursilería paternalista de las descripciones del libro, por parte de Darío, se entremezclan con algo que ese momento comenzaba a ser un peligroso movimiento, el feminismo y el sufragismo. Así L'ombre des jours es para el poeta un «flordelisado volumen de cosas bonitas, tiernas, melancólicas, femeninas, es un libro de mujer moderna con alma antigua. [Y así] La condesa de Noailles [nos] reconcilia con la literatura de cabellos largos, del sexo vilipendiado

\footnotetext{
12 Rubén Darío, «La Pardo Bazán. Un artículo de Unamuno» en Obras completas, tomo III, op. cit., p. 149.

13 Ibid., p. 150.
} 
intelectualmente por Schopenhauer» ${ }^{14}$. No es casual la cita del filósofo alemán que, con sus Parerga y Paralipómena (1851), había conseguido difundir sus teorías por los círculos culturales de Europa, y según el cual la mujer tiene una menor capacidad cerebral y es un ser de cabellos largos e ideas cortas, pues Darío, después de continuar con un párrafo de admirativo de la vida aristocrática de la condesa, que tanto disfrutó siempre («Es una joven exquisita, de veinte años, divina de frescura y gracia, que demuestra simplemente que se puede tener un nombre ilustre, un marido, un automóvil, vestirse en la calle de la Paix y poner su alma cantante y soñadora en las alas de los versos» ${ }^{15}$ ), subraya: «Nada tiene que ver esta sacerdotisa apolínea, o pánica con los pantalones del feminismo» ${ }^{16}$, porque según el escritor, Noailles se manifiesta en su poesía verlainiana y ha traspasado la dificultosa barrera del arte, tan imposible en una mujer aristócrata, dado que

La sostenida inferioridad ancestral, la ligereza, las preocupaciones mundanas, la maledicencia, la social inveterada hipocresía, el flirt moderno, las atenciones de la moda, las influencias religiosas y la agresividad intelectual masculina se presentan ante las tentativas de una vocación. Se necesita ser una voluntad, un carácter, para oponerse a todo eso, para luchar, para vencer ${ }^{17}$.

Claro que Darío percibe que se ha deslizado por el derrotero de la descripción de una mujer feminista y aclara para terminar el párrafo: «No me refiero, de ningún modo, a las agitadas y sonoras viragos del feminismo militante». Está clara la alusión a ciertos acontecimientos que, nacidos en el siglo XIX, se habían incrementado en el fin de siglo. El feminismo alcanzó una intensa justificación en Inglaterra con el libro El sometimiento de la mujer (1869) de Harriet Taylor y John Stuart Mill, que ofrecieron las bases sociales y filosóficas al movimiento sufragista, un movimiento que iniciado en Estados Unidos se difunde en Inglaterra a finales del siglo XIX y a continuación a todos los países europeos como la Francia en que

14 Rubén Darío, «A propósito de Mme de Noailles» en Obras completas, tomo I, op. cit., p. 300.

15 Ibid., p. 301

16 Ibid.

17 Ibid. p. 303. 
https://doi.org/10.46744/bapl.201802.009

Darío vive a partir de 1900. En 1889 se crea la Liga del Sufragio Femenino en Gran Bretaña por parte de Emmeline Pankhurst (1858-1928) que también había estudiado en París, y en 1903 organizó en Manchester la Unión Social y Política de Mujeres, cuyas actividades fueron tomando un cariz cada vez más agresivo. Tales ideas se difunden en la Francia de su época con gran participación femenina, la actividad de asociaciones como la Federación Francesa de Sociedades Feministas, La Unión Universal de Mujeres, y la celebración del Congreso General de Sociedades Feministas en París, en 1892; revistas como Solidarité des Femmes y La Femme de France, entre otras, alentaron la discusión y la exigencia de derechos ${ }^{18}$. El mismo Darío en este artículo ofrece testimonios suficientes del bullente mundo del feminismo en Francia en el comienzo del siglo XX.

Por eso, el poeta sienta la siguiente teoría: "Yo no creo en la igualdad espiritual del hombre y de la mujer» porque «La naturaleza es sabia ordenadora, y tiene sus leyes absolutas; en este caso la ley se llama fisiología», y puntualiza: "Creo, sin embargo, en que, así como hay hombres de alma femenina, hay mujeres de alma e inteligencia masculinas» ${ }^{19}$ — como la Condesa de Pardo Bazán, pensamos—. Y aunque manifiesta su desagrado por los gestos de la «literata, de la marisabidilla, de la cultilatiniparla de nuestro tiempo», lo que en español se define como «marimacho», dice preferir las mujeres de «buen lenguaje y de buena sopa» como las de señaladas damas francesas que cita ${ }^{20}$. Que la rebelión femenina ha sorprendido a Darío por su estridencia, lo prueba el que la referencia al libro de Mme. de Noailles ocupe una cuarta parte del total de un artículo que en realidad se dedica a hacer excursos acerca

18 Véase: Anne Cova, «El feminismo y la maternidad en Francia: Teoría y práctica política, 1890-1918» en Gisela Bock y Pat Thane (Eds.), Maternidad y políticas de género: La mujer en los estados de bienestar europeos 1880-1950, Valencia, Eds. Cátedra/ Universidad de Valencia, 1991, pp. 215-244; Anne-Marie Käppeli, «Escenarios del feminismo» en Georges Duby y Michele Perrot, Historia de las mujeres, tomo 4, Madrid, Taurus, 1993, pp.497-531.

19 Ibid. p. 304.

20 «Se habla de la sopa de coles de Mme. Dacier, una sopa famosa, aunque no tanto como la traducción de Homero de esa misma señora. La Scudery, la de Deshouillers, la de Genlis, la de Maintenon, la de Sevigné, la de Staël, muy plausibles mujeres de su casa. Les faltaría ortografía a algunas, pero orden doméstico, economía y ojo listo, eso no». Rubén Darío, «A propósito de Mme de Noailles» en Obras completas, tomo I, op. cit., p. 305. Las citas anteriores en la p. 304. 
de las mujeres escritoras y de los movimientos feministas en Francia. Las variedades de mujer que aprecia son muchas y, en efecto, se corresponden con los movimientos de su época: «hay la snob, la decadente, la wagnerista, la partidaria del amor libre, la Eva nueva, la doctora escandinava ibseniana y la estudiante rusa que tira balazos» y añade con ironía: «Confieso que prefiero las preciosas, que me quedo con Filaminta, con Belisa y con Armanda» ${ }^{21}$, es decir, «Las mujeres sabias» de Molière.

Una larga cita de nombres femeninos se sucede en el artículo de Darío como expresión de las mujeres de cultura en Francia, aunque es muy posible que en la enumeración quepa una vez más la ironía, pues reconoce que, aunque en menor cantidad que Inglaterra y Estados Unidos, escriben tanto en los periódicos como de ciencia y política, para enfatizar el intento de una «Academia de mujeres francesa» que propuso "cierta revista muy mundana» la revista Femina y concluir: «Solamente, si tal Academia llegase a realizarse, sería uno de los mayores triunfos del ridículo en la historia de las ocurrencias humanas. Ya hay bastante con el que ha caído durante tanto tiempo sobre la de 'inmortales' varones» ${ }^{22}$. Darío, contrario a las Academias, hunde en mayor ridículo y en un pozo de incomprensión el intento de las mujeres de las que entresaca dos o tres, y sobre todo a «esa rara Mme. Vallete, o sea Rachilde, [que] aparece como el cerebro femenino más complicado y vigoroso, no sólo de su siglo, sino de todos los $\operatorname{sig}^{2} \operatorname{los}^{23}{ }$. En definitiva, aunque nombres y aspectos citados en este artículo requerirían más espacio, la frivolidad con que el poeta nicaragüense encara el movimiento de las mujeres es más que evidente.

Y este tono se continúa con el artículo titulado «Niñas prodigios», en el que describe con gran tristeza los retratos y los dones de ciertas niñas precoces de Francia. Pero no es solo que manifieste tristeza por la infancia forzada al olvido antes de tiempo, sino que «en la mujer la

21 Ibid., p. 305.

22 Ibid., p. 306-7.

23 Continúa: «Hace unos diez años escribía yo de ella un retrato, en que mis entusiasmos de entonces iban hacia la parte extrañamente diabólica y misteriosamente pecadora de su obra. Hoy, con mayor reflexión, no veo a la escritora sadista — Sade toujours_, a la juglaresa incendiaria, sino a la sesuda y terrible filósofa, a la formidable destructora, a la Sybila de la anarquía» Ibid., p. 307. 
precocidad es más peligrosa aún. El fin de una superdespierta de diez años es terrible de pensar...» ${ }^{24}$, para pasar a hablar de ejemplos célebres como Jacqueline Pascal, y la precoz María Gaetana Agnesi, de la que concluye: "Ya se ve que ésta supera a todas nuestras cultilatiniparlas de la actualidad, estudiantas ibsenianas y feministas marisabidillas, y aun a nuestras más famosas doctoras y musas contemporáneas», entre las que en esta época se salvan sin ridículo de "saber chino a Judith Gautier y persa a Mme. Dulafoy» ${ }^{25}$. En definitiva, lo que llama "prostitución de la niñez» parece que se limita a las mujeres, llegando a considerar la excesiva precocidad «signo de degeneración» ${ }^{26}$. Da la impresión de que en realidad ese peligro es solo para las mujeres, y que el saber en la mujer, sobre todo si es niña o joven, es signo de degenerada decadencia, cosa que no es reconocida en el varón.

No sé hasta qué punto Darío tuvo noticia o pudo conocer algunas de las ideas expresadas en el libro del austriaco Otto Weininger, Sexo y carácter, que se publica en 1903 y cuyo contenido derivado de la misoginia romántica desde Hegel hasta Nietzsche, y de las ideologías fisiológicas que se difundieron a fines del XIX, le llevaron a explicar lo masculino como creativo y racional, y a lo femenino como irracional y caótico, con lo cual la mujer era vista como instrumento sexual y reproductor, y fundamentalmente destructivo de las fuerzas creadoras del varón. Tales ideas conectarían después con el nazismo emergente. Pero aunque no llegara a conocerlo, esos enfoques tenían tan ilustre y dilatada parentela en los autores más conspicuos del momento y en el siglo precedente que nunca se plantearía la necesidad de su revisión.

Entre las mujeres escritoras hispanoamericanas con las que tuvo relación Darío, destaca una peruana, hoy olvidada, Zoila Aurora Cáceres (1872-1958), que se atrevió a mantener una correspondencia con él — posiblemente parte de ella perdida- y a colaborar en la empresa de sus revistas parisinas. Nacida en Lima, era hija del general Andrés Avelino Cáceres (1836-1923), héroe en la época de

24 «Niñas prodigios», ibid., p. 312-3.

25 Ibid., p. 317.

26 Ibid., p. 320.

Bol. Acad. peru. leng. 64(64), 2018 / e-ISSN: 2708-2644 
la ocupación chilena, por cuyos servicios a la patria llegaría al grado de mariscal, a la vez que fue presidente de la República en dos periodos (1886-1890 y 1894-1895), y posteriormente ministro plenipotenciario del Perú en Europa. Su hija Aurora cursó estudios en su país natal y posteriormente en Inglaterra y Francia, mientras su padre ejercía como diplomático. En París fue alumna de la Escuela de Altos Estudios Sociales de la Universidad de la Sorbona (1902-1906), centro en el que se graduó. Llegó a tener, pues, una amplia formación que proyectó en la actividad pública con la fundación en Lima de varias sociedades, el Centro Social de Señoras en 1905, Evolución Femenina en 1911, Feminismo peruano en 1924, con el propósito de trabajar en favor de los derechos de las mujeres para las que pidió el derecho al voto, y, en los años de la Segunda Guerra Mundial la organización antifascista Acción femenina, a la par que fue conferenciante de temas sociales y culturales. Estas iniciativas evidencian sus inquietudes que se extendieron a las naciones de Europa al fundar en París y Madrid la Unión Literaria de los Países Latinos (1909) con proyección a los países hispanoamericanos, y luego en Lima la Asociación Nacional de Escritores y Artistas (1938), para ser representante del Perú en la Comisión Interamericana de Mujeres (1940-1945) con sede en Washington.

Como se puede observar en esta simple enumeración biográfica, Aurora Cáceres sobresale por su formación dentro del carácter subsidiario de la mujer en la sociedad peruana. Ni el ambiente ni la educación de las jóvenes propiciaban más que un acercamiento lateral, distante y diletante de las letras y de la cultura, y aunque pertenecieran a familias de renombre, era difícil romper las barreras de la sociedad y de la educación. Casi en la misma época otra peruana, Angélica Palma (1878-1935), acompañó a su padre, Ricardo Palma (1833-1919) en su viaje a España en 1892, vivió en Madrid de 1921 a 1925 y alcanzó un destacado reconocimiento como escritora con sus novelas, ensayos y crónicas $^{27}$. Pero no llegó tan lejos como Zoila Aurora Cáceres que mantuvo correspondencia con Rubén Darío y con Miguel de Unamuno implicándoles en sus proyectos y actividades.

27 Martínez Gómez, J. y A. Mejías Alonso, Hispanoamericanas en Madrid (1800-1936), Madrid, Dirección General de la Mujer/ Horas y Horas la Editorial Feminista, 1994, pp. 145-147. 
Resulta irónico que mujer de tan arraigadas convicciones feministas haya pasado hasta ahora a la historia por su relación con dos hombres. Primero, la figura de su padre del que fue secretaria durante su estancia en Europa, y cuyas memorias recogió en el volumen La campaña de La Breña (1921) y en el Anecdotario (1950-1951), con importantes anotaciones de su actuación política y militar. Y, luego, por su matrimonio en 1906 con el escritor guatemalteco Enrique Gómez Carrillo (1873-1927), cuya relación y posterior rompimiento aparece reflejada en su libro Mi vida con Enrique Gómez Carrillo (1929), libro apasionado y testimonial escrito a modo de diario epistolar que empieza en 1902 cuando lo conoce en París. El prólogo de Manuel Ugarte (1974-1951), el escritor argentino residente en la misma ciudad, pone en su lugar la fama del escritor «a pesar de la zona frívola en que él mismo quiso encastillarse», para resumir que era «un endemoniado de la literatura, víctima de sus propias jactancias» ${ }^{28}$; un reconocimiento que no impide que valore la personalidad y la obra de Cáceres que «supo mantener una luz de piedad comprensiva y desinteresado amor ${ }^{29}$ por el bohemio escritor modernista. El libro fue apreciado en España como lo prueba la reseña de Benjamín Jarnés en la Revista de las Españas que lo considera "pulcramente escrito, cautamente velado en aquellos trances donde pudiera haberse detenido torpemente la malicia del lector» y como «documento de excepción para conocer la vida privada y aún la gestación y vicisitudes de la pública vida literaria del inquieto cronista» ${ }^{30}$. Sin embargo, también ha sido juzgado con acritud al traspasar la barrera de los comentarios personales:

Sorprende a los biógrafos que el escritor se haya enamorado tan fugazmente de una mujer cuyo carácter autoritario y hosco temperamento eran tan distintos de los suyos. Nada había en la personalidad de la hija del Mariscal peruano que mostrara similitud alguna con la de Gómez Carrillo [...] Puede decirse hoy que la peruana puso en juego los artilugios femeninos para hacer caer al escritor en su red ${ }^{31}$.

28 Aurora Cáceres, Mi vida con Enrique Gómez Carrillo, Madrid: Renacimiento, 1929, pp. 7-8.

29 Ibid. p. 9.

30 Citado por Juana Martínez Gómez, op. cit., p. 151.

31 Alfonso Enrique Barrientos, Gómez Carrillo, 30 años después, Barcelona, Ediciones. Rumbos, 1958 , p. 109. 
Sin embargo, la más que acentuada complicidad masculina de estos comentarios se ha desvanecido con los años y con el mejor conocimiento de la vida de Gómez Carrillo, por lo que la figura de Aurora Cáceres puede ser interpretada con la justicia que le corresponde, como una persona cuya dignidad no pudo soportar los considerables abusos de su pareja.

La obra literaria de Aurora Cáceres apenas resulta conocida y por consiguiente carece de estudios aproximativos, sin embargo, su trabajo literario se inició en el periódico El Comercio de Lima bajo el seudónimo de «Evangelina», y se prolongó luego en relatos y crónicas. Aparte de las obras citadas publicó: Mujeres de ayer y boy (1909); los relatos La princesa Sumac Tica (1929), las novelas La rosa muerta (1927) y Las perlas de Rosa (1930), así como Oasis de arte (1912) y La ciudad del Sol (1927), en los cuales recogió crónicas de viaje y sus impresiones sobre Cuzco. Tres de estos títulos le fueron enviados a don Miguel de Unamuno y constan en su biblioteca. En cambio, es difícil saber cuál fue la verdadera relación con Rubén Darío, aparte de lo que nos evidencian sus escasas cartas y el prólogo que le dedicó el nicaragüense. Son cinco las misivas cruzadas entre ellos, casi todas breves, dos tarjetas, dos notas y una carta, al parecer escritas cuatro de ellas en París, y la quinta en Berlín, donde acompañaba a su padre, el General Cáceres, porque, aunque carecen de fecha, corresponden a la época en que Darío aceptó dirigir la revista Mundial en 1911, que le proponen los empresarios uruguayos hermanos Guido, y también otra revista dedicada a la mujer, Elegancias. No me parece, por tanto, pertinente el juicio riguroso de Luis Alberto Sánchez al prologar el libro de Willy Pinto Gamboa, Epistolario de Rubén Darío con escritores peruanos, cuando expresa:

Zoila Aurora Cáceres (Evangelina) aparece en esta colección con varias cartas, pero todas ellas banales. Se refiere a encuentros con Rubén y a datos sobre su propia vida en París y en Berlín. El compilador ha hecho bien en agregar al texto la crónica de Rubén sobre el matrimonio de Zoila Aurora con Enrique Gómez Carrillo, a quien Darío amaba y temía por 
https://doi.org/10.46744/bapl.201802.009

su estilo de vida tempestuoso y sus expresiones generalmente lapidarias y adversas a él ${ }^{32}$.

De nuevo la complicidad masculina y el menosprecio de la labor de las mujeres, esta vez ya mediado el siglo XX, y cuando es sabido que Gómez Carrillo no fue precisamente el esposo ideal. Pero en todo caso, no es posible hacer juicios apresurados, ya que nunca será fácil saber el número de cartas que cruzaron y la importancia real de su relación; solo se puede constatar que la correspondencia de Aurora Cáceres se inserta en esta empresa parisina de Darío, pues la primera misiva hace referencia a las revistas para las cuales la autora peruana podía resultar propagandista y colaboradora de importancia por la facilidad con que se movía en los círculos aristocráticos de la sociedad europea. De ello estaba persuadido Darío, estamos seguros. Dada la ausencia de fechas, puede hacerse tan sólo una cronología aproximada por su contenido, y así parece que la primera tarjeta fechada el 1 de abril debe corresponder al año 1911, pues le comunica que se quedará algunos días más en París y que espera «tener el gusto de verle y de poder hablarle respecto a las revistas que Usted dirige» ${ }^{33}$. El tono resulta siempre respetuoso y admirativo y la despedida se inserta con un «Reciba Usted el más atento y afectuoso saludo de su sincera amiga. Aurora Cáceres». La siguiente tarjeta es una nota que da a entender que Evangelina ha emprendido alguna actividad a favor de la difusión de las revistas de Darío, tan necesitado de solvencia económica que, es sabido, los empresarios Guido le obligaron a realizar de abril a noviembre de 1912 una gira propagandística de sus revistas por varias ciudades de Europa y de América. Por eso, de modo apresurado, Aurora Cáceres le hace saber dos direcciones de dos damas de la sociedad parisina ${ }^{34}$ cuya causa había ganado para suscribir las revistas

32 Willy Pinto Gamboa, Epistolario de Rubén Darío con escritores peruanos, Universidad Nacional de San Marcos-Universidad de Chile, Lima, 1967, p. 12.

33 En todos los casos de las cartas de Aurora Cáceres las transcribimos de Archivo Rubén Darío, Universidad Complutense de Madrid, que dirige Luis Sáinz de Medrano, a quien agradezco las facilidades.

34 «La invitación a la condesa Gloria Fca? di Brugno se la pueden mandar a la Rue Cléber 67 y la de la Sra Rosa Finaly -donde la de Catulle Mendes, Hotel Palais d' Orsay. Justino de Montalvao (20 rue de Longchanp) ya está advertido. M. Ferdinand Gavary está fuera, ya averiguaré cuando llegue. Le saluda afectuosamente su amiga Aurora» (La carta está fechada el 14 de abril en el sello, tal vez de 1911). 
del nicaragüense. El tercer documento es una nota en la que brevemente le comenta:

Muy distinguido amigo: Por Bonafoux he sabido que deseaba V. hablar conmigo a propósito de la Elegancia lo que me procurará el placer de verle. Tenga la bondad de decirme lo más pronto que sea posible cuando le encontraré en su casa, para ir a hablar con V. Yo permaneceré muy pocos días en París, pues vamos a Berlín donde papá ha sido nombrado ministro. Le envía un afectuoso saludo su amiga Aurora Cáceres.

Parece curioso que sea precisamente el escritor español Luis Bonafoux (1855-1918) ${ }^{35}$ el intermediario entre ambos; sin embargo, sabemos que tuvo una buena relación con ella y que llegó a prologarle el primero de sus libros, Mujeres de ayer y de hoy, en 1909. Bonafoux, que residía en París, introduce el libro con «Unas palabritas...», prólogo atípico que no evita el paternalismo y la sensación de compromiso, al destacar la valía de la autora y sus buenas relaciones con el mundo literario en Madrid y en París. Baste una muestra: «Con titularlo Feminismo hubiera bastado, porque eso es el libro: del Feminismo en Europa y América» y precisa: «semblanzas típicas, interesantes y bonitas; libro de historias femeninas, de anécdotas falderas, seleccionadas con tacto de artista y presentadas con discreción de dama» ${ }^{36}$. Como se puede observar, aunque bien es cierto que el libro alcanza escaso nivel en su combinación histórica y personal, y solo tiene la valía que infunde su mirada de mujer, la autora vuelve otra vez a encontrar el paternalismo, la minusvaloración irrespetuosa y la ironía masculina.

La cuarta carta que conservamos parece ofrecer un nuevo matiz en la relación con Darío, pues de un «estimado amigo» pasa a trazar, como también la quinta carta, un «Muy estimado y admirado amigo» y un «Muy estimado y admirado poeta» respectivamente, y no solo eso, sino que en esa cuarta carta se permite una iniciativa al proponerle una cita para tomar

35 Conocido por su periodismo virulento y sus radicales opiniones sobre política y literatura, su obra comienza con Ultramarinos (1882) y luego, entre otras, Bilis (1908), Clericanallas (1910), Españoles en París (1912).

36 Aurora Cáceres, Mujeres de ayer y de hoy, Paris, Garnier, s.f., [1909], p IX. 
el té en su casa antes de volver a Alemania, pues «Se encuentra de paso en esta un joven escritor peruano de gran talento y de fortuna en el que todos los peruanos vemos un gran elemento de utilidad para la patria. Yo desearía presentarle a V. a este amigo quien admira a V. tanto como yo». Es decir que Aurora Cáceres también tomaba las riendas sociales a la hora de presentar al poeta a otros escritores. No sabemos qué escritor era y si Darío accedió a la visita. En la última carta, la más extensa y ya desde Berlín, se confirma el interés de Aurora Cáceres en la colaboración en Mundial («Sólo hoy me es posible enviar a V. una correspondencia, para Mundial, conforme le ofrecí en París. Ojalá sea de su agrado!»). Es esta la carta más expresiva, en la que le llega a hacer alguna observación personal y que se sale de las notas de colaboración empresarial, «Desde que llegué a Berlín he estado sin trabajar, esta ciudad me entristece de tal modo que siento el espíritu como muerto», le dice dándole cuenta de su estado de ánimo; o indicaciones sobre su itinerario que incluyen las visitas a Munich para visitar a las Infantas Isabel y Paz y luego los viajes a Montecarlo y París. Y lo que debía importarle más, sus publicaciones: se queja de no haber recibido ninguna de sus revistas, Mundial, ni Elegancias, y de no saber si ha aparecido el retrato que le remitió, así como, más importante, el prólogo de Darío a su libro Oasis de arte:

Hace algunas semanas me escribieron de la casa Garnier que sólo esperaban el prólogo de V. para que apareciese mi libro Oasis de Arte. Sus múltiples ocupaciones le han dejado un momento para dedicarme unas líneas? Qué dicha si así fuere!

Como los hombres dominaban la vida literaria, en su deseo de hacerse un lugar en ella, Aurora Cáceres había encontrado la oportunidad de pedirle un prólogo a Rubén Darío. Es más que evidente que este sintió en esos momentos el peso del compromiso acerca de una escritora que se había comprometido a ayudarle en la difusión de sus revistas, y ello lo obligó a escribir el prólogo en un momento en que —estamos en 1912Aurora Cáceres realiza su primer viaje a España, país en el que colaboraba en $A B C$ y Blanco y Negro con su seudónimo de «Evangelina» ${ }^{37}$, por lo

37 Juana Martínez Gómez, op. cit., p. 82. 
que fue invitada a las reuniones sociales, a impartir una conferencia en el Ateneo sobre el tema de «España en la poesía del Perú» y a colaborar en importantes revistas de la época, como la Revista de las Españas ${ }^{38}$. Estos éxitos también debieron estimularla, y Oasis de arte aparece en este año, reuniendo crónicas de viajes por Europa, Suiza, Italia, Francia, Bélgica, Alemania, y adjuntando también la conferencia que impartió en la Sorbona acerca del Perú, que es quizá la parte mejor del libro.

Rubén, por tanto, no tiene más remedio que escribir el prólogo solicitado. Como hemos observado, el nicaragüense tenía una idea negativa de las mujeres escritoras, cosa que se evidencia en el prólogo en unas líneas que tampoco nublan su desaforado machismo: «Confieso ante todo que no soy partidario de las plumíferas; que Safo y Corina me son muy poco gratas», para continuar:

Una Teresa de Jesús, o una George Sand, me parecen casos de teratología moral. Ahora, una literatura discreta, un escribir como se borda, o se cuida una flor; una manifestación de impresiones y sensaciones, sin dogmatismos ni pedanterías, confieso que suele ser en ocasiones no solamente excusable sino encantador.

Y sigue en plan jocoso al afirmar que no le gustan las mujeres de letras porque «con ciertas excepciones, han sido y son feas [aunque] Evangelina no se encuentra en este caso, pues ha sido y es gala de los salones, tanto por su espíritu como por su beldad, gracia y elegancia. Baste con decir que es una compatriota de Santa Rosa de Lima» ${ }^{39}$. Humor, ironía que roza la falta de respeto so capa del elogio, aunque es posible que ni la propia autora lo considerase vejatorio, al ser ese tono el característico que empleaban los escritores para con unas publicaciones

38 Martínez Gómez y Mejías Alonso dan cuenta de su actividad literaria y periodística en el Madrid de esos años; su recibimiento en los salones de Pardo Bazán, y la notoriedad que alcanzó su conferencia del Ateneo a la que asistieron ministros de Estado y los enviados americanos al Centenario de las Cortes de Cádiz (Juana Martínez Gómez, op. cit., pp. 149-151).

39 Aurora Cáceres, Oasis de arte, Paris, Garnier, s.f. [1912], pp. VII-VIII. El texto se publica en Variedades de Lima el 20 de julio de 1912, al parecer con alguna variante pues la palabra plumíferas en la frase que citamos, se sustituye por sabibondas. Quizá le pareció excesivo. 
que consideraban pueriles, aniñadas e inconsistentes. Que el compromiso era ineludible lo prueba incluso que la mayor parte del prólogo del poeta sea una enumeración fatigosa de los lugares por los que se detiene Aurora Cáceres en su libro, y que tiene por fin cubrir líneas sin decir nada, para ocupar el resto del espacio con la transcripción de un largo párrafo de la autora con el mismo fin de escribir lo menos posible y cubrir el expediente. Como valoración total de su trabajo sólo quedan para Darío «ocurrencias candorosas» y algunas descripciones estéticas que al final se reducen a un solo párrafo, el que cita.

También el propio Rubén Darío había reflejado por escrito, en junio de 1906, la boda de Aurora Cáceres con Gómez Carrillo, gracias al cual, es muy posible, ella conociera personalmente al escritor. El artículo, en plan jocoso y desenfadado, como escrito para una revista de variedades, «Carrillo, casado», se centra en el escritor guatemalteco, manifestando la perplejidad que tal situación le producía, a la vez que se erigía en su guía espiritual y cultural:

Vengo del matrimonio de Gómez Carrillo. Gómez Carrillo casado! Vida bien llenada con lo que falta. Y veo al joven que conocí en Guatemala hace ya muchos años. Era yo director de un diario político que consagraba su mayor parte a la literatura. Tenía como colaboradores a los principales jóvenes que entonces sabían halagar a las musas en aquella tierra amable. [...] Me complazco en haber hecho cambiar de rumbo aquel talento primaveral y en haberle señalado el camino de esta Galia que debía adoptarle por hijo espiritual ${ }^{40}$.

Aunque no deja de ironizar sobre su trayectoria personal: «Ha tenido, entre tanto, muchas aventuras, muchas originalidades...»; sobre su fama: «Se ha hecho famoso, ha escrito muchos libros y una cantidad fabulosa de artículos en la prensa española y americana»; y sobre sus veleidades y ataques al propio Darío: «Ha representado la comedia del

40 Willy Pinto Gamboa, Epistolario de Rubén Darío con escritores peruanos, op. cit., p. 60. El artículo ocupa las páginas 60 a 62. Fue publicado en En Monos y Monadas. Año I, núm. 44, Lima, 27 de octubre de 1906. 
amor, la del odio, la del duelo, la de la bohemia, la de la diplomacia; ha escrito la célebre frase: "Cuando Rubén Darío tenía talento...». La descripción de la novia nos interesa por su inconsistencia, pues, desde luego, no es más que un trazo estético al que se añade un irónico valor: «La novia es de hermosos ojos, graciosa, voluptuosa. Es también literata». Y tras «el discursito» del alcalde con todos los tópicos de semejantes casos y alusiones al famoso padre de la contrayente termina el artículo como una crónica de sociedad en la que puede haber algún trazo premonitorio:

Ya Carrillo está casado. Ya partimos los concurrentes al Hotel Royal, donde almorzamos y nos regocijamos. Las frases son frescas y sabrosas. Hay una dama linda y enlutada. Ríe una niña que es como un querubín. El champaña acapara sol en las copas. Luego todos nos despedimos. El General siempre nervioso, se retuerce el bigote; se va a Roma. Carrillo con su novia se va probar la miel de la luna. Y todo esto está perfectamente.

Tal vez un breve resumen de la relación de Aurora Cáceres con Unamuno puede ser beneficiosa para valorar a la autora y el concepto que los escritores de la época tenían sobre las mujeres escritoras, y así contrastar con la de Darío. Es muy posible que la peruana también conociera a Unamuno a través de su esposo Enrique Gómez Carrillo, pues anota en su libro Mi vida con Enrique Gómez Carrillo que este recibe una carta del Rector de Salamanca fechada el 2 de octubre de 1906, que transcribe por extenso. Que la figura de Unamuno le causaba tremenda admiración no cabe ninguna duda, y como prueba de ello tenemos tres cartas que corresponden a los años 1909 y 1928, aparte del envío de tres títulos de su autoría ${ }^{41}$. Cáceres le habla a Unamuno en las dos primeras cartas de su proyecto de la fundación de la Unión Literaria, de la que se ofrece a enviarle los estatutos, consciente de la dificultad de la empresa, de la que ha emprendido una amplia campaña propagandística en los medios parisinos. Al mismo tiempo le remite una conferencia suya, pues «su sabia opinión me será de gran provecho y la estimo tanto cuanto vale por su ciencia y sinceridad». La segunda

41 Tanto las cartas como los tres libros citados, Mujeres de ayer y hoy, Oasis de arte y La ciudad del sol de Aurora Cáceres se encuentran en la Casa Museo Miguel de Unamuno de Salamanca. 
carta abunda en la estrategia para lograr el cometido y se observa que la escritora demuestra una sincera preocupación por el progreso y por las buenas relaciones entre letras de los países de América y España. Es decir que al menos en la correspondencia que se nos conserva a través de las cartas a Unamuno podemos observar la verdadera actividad de la escritora peruana, preocupada no solo por las reivindicaciones feministas y su propia obra, sino por las relaciones culturales entre los pueblos. Y respecto a la opinión de Unamuno, nada mejor que acudir al libro de Aurora Cáceres, La ciudad del Sol ${ }^{42}$, aparecido en Lima en 1927 y dedicado a quien había sido su esposo, Enrique Gómez Carrillo, que había fallecido recientemente. De él coloca como prólogo un artículo publicado en $\mathrm{La}$ Razón de Buenos Aires, en 1924, en el que Carrillo comenta su obra con la misma cursilería infantil que venimos observando, para no decir lo que verdaderamente piensa, que su obra no tiene validez alguna. Una frase puede servir de ejemplo: «Muy en el fondo, su espíritu católico no deja de sentir escrúpulos de antigua colegiala del Sagrado Corazón, al notar que sus labios murmuran, inconscientemente, las preces solares» ${ }^{43}$. Pero lo que más nos interesa no es en este caso la opinión de Gómez Carrillo, sino que en este libro, en su parte final, recoge una serie de juicios de amigos y escritores que resaltan su valor, entre ellos el de Unamuno, que valora su obra, tal vez refiriéndose a Oasis de arte y que tal vez proceda de una carta personal:

Tanto como en general me fastidian las escritoras, gusto de las mujeres que escriben como Ud, amiga mía. El desarrollar la distinción sería larga cosa; Madame Sevigné era una mujer que escribía; Madame Stael, una escritora y pocas cosas gusto más sus breves y repetidos relatos de viaje y es lo que mejor cuadra a una mujer, la impresión rápida del detalle, el sentido de lo real ${ }^{44}$.

Palabras que podemos incluir también dentro de esa concesiva subalternidad en la que caen los juicios masculinos acerca de

42 Aurora Cáceres, La ciudad del Sol, Lima, Librería Francesa Científica y Casa Editorial Rosay, 1927.

43 Ibid. p. 14.

44 Ibid. p. 179-180.

Bol. Acad. peru. leng. 64(64), 2018 / e-ISSN: 2708-2644 
las escritoras, y hasta incluso puede interpretarse el párrafo final como irónico, dentro de la seriedad característica del vasco, cuando alude al prólogo de Rubén Darío: «tiene razón Rubén: el párrafo que le reproduce es lo mejor del libro... Gracias por su presente, nos ha hecho pasar unos buenos ratos hasta cuando ha excitado mis viejas antifobias». Como vemos, Unamuno se solidariza con Rubén y aunque, más cuidadoso, las opiniones son coincidentes ante una personalidad que se contempla como feminista, aunque sea aburguesada, y una obra que, bien es cierto, nunca alcanzó el nivel estético de los varones de su época, pero que cuya labor siempre fue dirigida con esfuerzo y tenacidad.

Nos gustaría completar la visión de las mujeres escritoras en Rubén Darío con las referencias a otros casos, aunque no seamos exhaustivos, porque estos datos completan y precisan la perspectiva del tema que tratamos. En Semblanzas de 1912, dedica un artículo a la cubana Dulce María Borrero ${ }^{45}$, abordando los tópicos habituales de la poesía de la autora, romanticismo, tema amoroso, sensibilidad, a lo que añade: «Sus imágenes son usuales, sus fórmulas son conocidas: lo que brilla es el diamante personal, o, mejor dicho, en este caso, la lágrima» y remacha con intencionalidad: «escribe a suspiros; 'suspirillos', diría el ya olvidado Núñez de Arce» — recordemos que lo dijo acerca de Gustavo A. Bécquer - aunque en este caso la valoración cobra fuerza a traer a colación a «la genial uruguaya Delmira Agustini», con la que, en efecto, mantuvo correspondencia y cuyas palabras Agustini introdujo como "Pórtico» de su libro Los cálices vacíos de 1913. No se puede dudar de la admiración que Rubén Darío sintió por la uruguaya bien expresa en sus palabras, aunque no evite el sesgo paternalista que infantiliza a la mujer:

De todas cuantas mujeres hoy escriben en verso ninguna ha impresionado mi ánimo como Delmira Agustini, por su alma sin velos y su corazón de flor. [...] Si esta niña bella continúa en la lírica revelación de su espíritu como hasta ahora, va a asombrar a nuestro mundo de lengua española.

45 Rubén Darío, «Dulce María Borrero de Luján, una poetisa cubana» en Obras completas, tomo II, op. cit., pp 879-882. 
https://doi.org/10.46744/bapl.201802.009

Sinceridad, encanto y fantasía, he allí las cualidades de esta deliciosa musa $^{46}$.

Tenemos que conceder que, aun en los elogios, nunca hubiera empleado Darío ese lenguaje para un hombre que escribiera. Y dentro del apartado de los elogios también en su volumen Letras de 1911, al hablar de la obra de Eugenia de Guerin ${ }^{47}$ y el maravilloso arcaísmo de su escritura, se insertan opiniones como que su prosa se desliza «a modo de un agua de la fuente» y que en ella habitan «corderos de amor divino», y «candidez celestial», para concluir que sus versos son «inocentemente románticos». Expresiones que brotan de su conservadurismo religioso al tratarse de una mujer que dedicó su vida a convertir al catolicismo a su hermano el escritor Mauricio de Guerin (1810-1839), autor de un famoso poema, El Centauro (1840).

Pero el gran peligro siguen siendo las feministas, pues en un breve artículo, casi un apunte, titulado «iEstas mujeres! ${ }^{48}$ de Todo al vuelo de 1912, en el que en forma chistosa alude a cómo en Francia las mujeres quieren votar siguiendo el ejemplo de Inglaterra, vuelve a sacar el tópico que ya había esgrimido con anterioridad, pues ante las fotos de esas mujeres enjuicia: "Como podréis adivinar, todas son feas; y la mayor parte más que jamonas. El feminismo les ha encendido el entusiasmo». La descripción que continúa roza la grosería al rebajar los actos de ciertas mujeres que exigen el voto femenino. Pero también se muestra concesivo y reconoce la sabiduría de Mme. Curie, que sabe tanto como su marido, el arte de Sara Bernhardt que «merece la Legión de Honor, como artista, más que cualquier afeitado o barbudo»; que «una que otra virago se ha distinguido en exploraciones e incursiones por tierras salvajes o lugares inaccesibles»; que otras «se dedican a esos sports como a cualquier otro, y hay musas muy recomendables. Pero estos marivarones -suavicemos la palabra.. que se hallan propias para las farsas públicas en que los hombres se distinguen» no le son aceptables en modo alguno, son

46 Delmira Agustini, Poesías completas, edición de Magdalena García Pinto, Madrid, Cátedra, 1993 , p. 223.

47 Rubén Darío, «Eugenia de Guerin» en Obras completas, tomo I, op. cit., pp. 520-528.

48 Rubén Darío, «iEsas mujeres!» en Obras completas, tomo II, op. cit., pp. 549-552. 
dignas del desprecio. Discurre con propiedad masculina que pudiera haber abogadas «iPero las alcaldesas, diputadas y senadoras! Ello pasa de lo aristofanesco!», y concluye: «las propagandistas son solamente unas cuantas, viejas y feas» y «Las demás mujeres, de belleza o de gracia, seguirán ejerciendo el único ministerio que la ley de la vida ha señalado para ellas: el amor en el hogar o el amor en la libertad».

Es cierto que Darío no hacía más que seguir las opiniones de la época, que nada le estimulaba al cambio de perspectiva, pero, con todo, se observa un progresivo exacerbamiento, una inquietud, y, en consonancia, una respuesta más contundente e irónica. La lucha de Aurora Cáceres quedó en el olvido; su obra, a remolque de los nombres masculinos que se cruzaron en su vida; difuminada su actividad, su tenacidad y su esfuerzo. Quizá sea la hora de comenzar otra historia literaria, la de los nombres secundarios, y, por tanto, de las mujeres que emprendieron tareas incomprendidas en su época. 